\title{
Bench to bedside: The technology adoption pathway in healthcare
}

\author{
Daniel Clark $^{1}$ (D) $\cdot$ Gerard Dean ${ }^{1} \cdot$ Sarah Bolton $^{2} \cdot$ Beth Beeson $^{1}$
}

Received: 31 May 2018 / Accepted: 22 August 2019 / Published online: 19 October 2019

(C) The Author(s) 2019

\begin{abstract}
New technologies have the potential to revolutionize the way we manage health and wellbeing now and in the future. But often seen as expensive and difficult to implement, the challenge is to identify the best technology to deliver real patient benefit and support its rapid adoption to help address the funding difficulties faced by all modern healthcare systems. In this paper we consider the traditional linear model of the technology adoption pathway as it pertains to healthcare, look at common challenges faced traversing this path and suggest solutions. In so doing, we recognise the limitations of the linear model and describe our version of a more realistic, non-linear model. Throughout, we will be looking at the key role of the Clinical Engineer to successful healthcare technology adoption based on our experience of supporting medical device products through to adoption and present the key lessons we learnt along the way.
\end{abstract}

Keywords Healthcare technology $\cdot$ Technology adoption pathway $\cdot$ Clinical engineer

\section{Introduction}

Modern healthcare is ever more dominated by technologies: technology has a role in hospitals and in community settings; in acute episodes and chronic care and indeed technology can be used to prevent people becoming unwell in the first place and help us all live longer, healthier lives. New technologies have the potential to revolutionize the way we manage health and wellbeing now and in the future. But often seen as expensive and difficult to implement, the challenge is to identify the best use of technology to ensure it can deliver real patient benefit and support its adoption to help address the funding difficulties faced by all modern healthcare systems.

Currently, there is something of a funding crisis in the NHS in the UK. Estimates vary but the deficit could be as much as $£ 30 \mathrm{bn}$ in the next few years [1]. And it's not just the NHS or the UK facing this crisis, healthcare systems all over the globe, and particularly in the developed world, are struggling to find sustainable business models. As a population we are getting

Daniel Clark

Daniel.clark@nuh.nhs.uk

1 Clinical Engineering, Nottingham University Hospitals NHS Trust, QMC Campus, Derby Road, Nottingham NG7 2UH, UK

2 CHEATA (Centre for Healthcare Equipment And Technology Adoption), Nottingham, UK older, fatter and more prone to long-term diseases like diabetes, coronary heart disease, and dementia. Our life expectancies have risen sharply over the last couple of decades and our demands on the healthcare system have risen even more so. We now expect to be treated for, indeed cured of, conditions and diseases that a generation ago we were prepared to live with and indeed die from. And this is of course a really good news story. As an industry, healthcare has been incredibly successful, but we are now, in many ways, the victims of our own success: there are more and more people, expecting more and more healthcare and the cost of meeting this expectation is increasing much faster than the resources we have at our disposal.

Since the publication of the UK Government white paper 'Innovation Health and Wealth' [2] in 2011, much has been made about the possible benefits of introducing new technology, both in terms of improved patient outcomes and improved productivity. Indeed, it is suggested that much of the $£ 30$ bn funding gap predicted in the NHS could be reduced with the adoption of appropriate technology. But research into new technologies, development from concepts to finished medical devices manufactured and distributed to the point of need, can be challenging and expensive. Navigating this adoption pathway, sometimes referred to as 'Bench to Bedside', in an efficient and timely manner is key to success. In this paper we explore the technology innovation pathway as it pertains to healthcare. We consider the traditional linear model of the 
technology innovation, look at common challenges faced traversing this path and suggest solutions. In so doing, we recognise the limitations of the linear approach and describe our version of the more realistic, non-linear model. Throughout, we will be looking at the key role of the Clinical Engineer to successful healthcare technology adoption based on our experience of supporting medical device products through to adoption.

\section{The technology adoption pathway - the linear model}

One of the first (conceptual) frameworks developed for understanding the relation of science and technology to the economy has been the linear model of innovation. The model postulates that innovation starts with basic research, is followed by applied research and development, and ends with production and diffusion. The precise source of the model remains nebulous, having never been documented. Several authors who have used, improved, or criticized the model in the past fifty years rarely acknowledged or cited any original source [3]. The model has been presented in various forms but we choose to define it as two main phases - Invention and Implementation - divided into a further 7 stages to describe as illustrated in Fig. 1.

\subsection{Invention phase}

The first three stages of the Invention Phase (Conception, Creation and Confirmation) can be grouped into what is often referred to as the Design and Development phase. There is significant discussion in the literature [4] on the design and development process and we don't intend to review this here. Instead, we present our version of the Design and Development process as we apply it to medical device development (see Fig. 2). We make no claim of novelty or uniqueness but find this presentation simple and easy to apply model for our development work and reproduce it here to illustrate this part of the pathway.

The starting point for any new technology is the idea, the spark, the recognition of the need and the postulation that it might be met with some new product or service. In our version of the pathway we refer to this as the Intent. In the healthcare setting this typically represents an unmet (or poorly met) healthcare need and can be generated by a clinician, an engineer or scientist or indeed a patient or member of the public. One of the great challenges for medical devices innovations is to bring together this identified need with a potential solution: the patient struggling with a condition or the clinician with a diagnosis challenge or a limited treatment options are likely to be unaware of the scientific research techniques and methods that the academic teams take for granted. Similarly, the research scientists and engineers pushing the boundaries of their respective fields might have no idea of the complex medical and healthcare challenges to which their discoveries might be applied. All too often we rely on chance meetings or serendipitous encounters to create that spark. An example of this ad hoc 'sparking' from our own experience resulted in the successful development of a novel neonatal heart rate monitor. A university-based engineering research team were developing a pulse sensor to be fitted into the hard hats of miners working in extreme conditions to act as an early warning alert. They were presenting their work at a lunchtime seminar when a neonatal consultant just happened to be in the room for other reasons and saw the presentation. The medic asked if the technology could be transferred to the hats worn by premature babies and the engineering team thought, why not. What followed was a major success story of collaborative research and ultimate product release and supply across the NHS; it all started through this chance meeting [5]. We need to remove the element of chance from stories like these by creating opportunities for researcher and clinician to meet more often, and the clinical engineer has a key role to play here. Being embedded within the healthcare provider but also having the skills, experience and language needed to engage with academic research teams, clinical engineers have the opportunity, indeed the duty, to facilitate the meeting of these stakeholders. Generally, a variety of means are required from formal seminars and conferences to informal gatherings where conversations often naturally develop into research proposals. We have a lot of success, for instance, arranging informal dinners where academics and clinicians meet, enjoy good food and drink and, with careful and gentle coaching and encouragement and the right mix of backgrounds and experience, generate the perfect environment for 'organised serendipity'.

It is important to capture the outcome of these 'sparkings' in some form of a Definition Document. Style and format can vary but essentially this is the design brief and should include detail of features that are essential and desirable. The input of human factors into the design process is becoming increasingly prevalent and is now mandated in the new medical device regulations [6]. Generally, the Clinical or Biomedical Engineer is best placed to capture this being able to understand both the healthcare and the technological context. We refer to the next stage, which takes this design brief and produces a prototype, as the Creation stage. This is probably the best understood part of the pathway, at least by engineers, and is very much the 'bench' end of the Bench to Bedside pathway. Details of the tasks will of course be dependent on the basic science and the application but there is always a series of iterative loops as designs are tested, modified, re-tested, redesigned and developed. At various points during this stage it will be necessary to verify that the design delivers performance that meets the specification of the design brief. There might be one or many loops around the verification circuits to 
MEDICAL DEVICE TECHNOLOGY TRANSFER

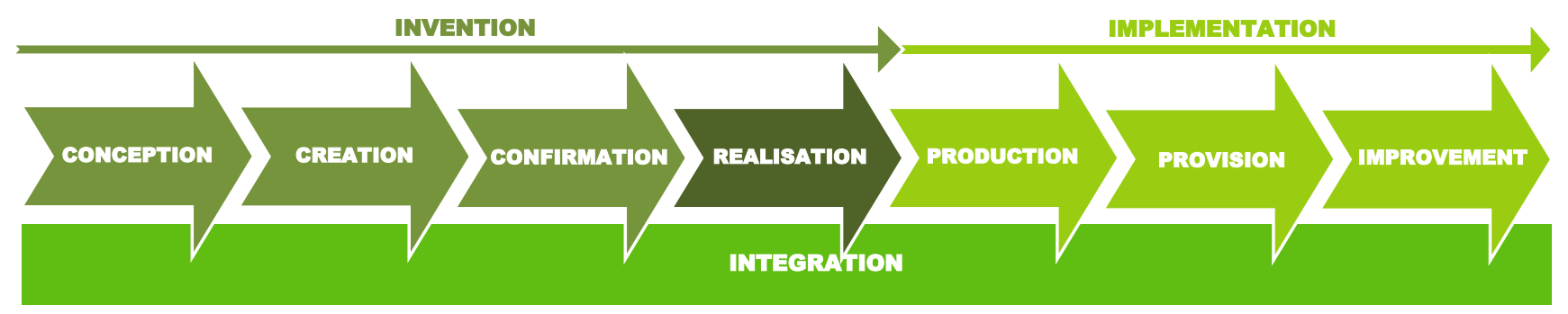

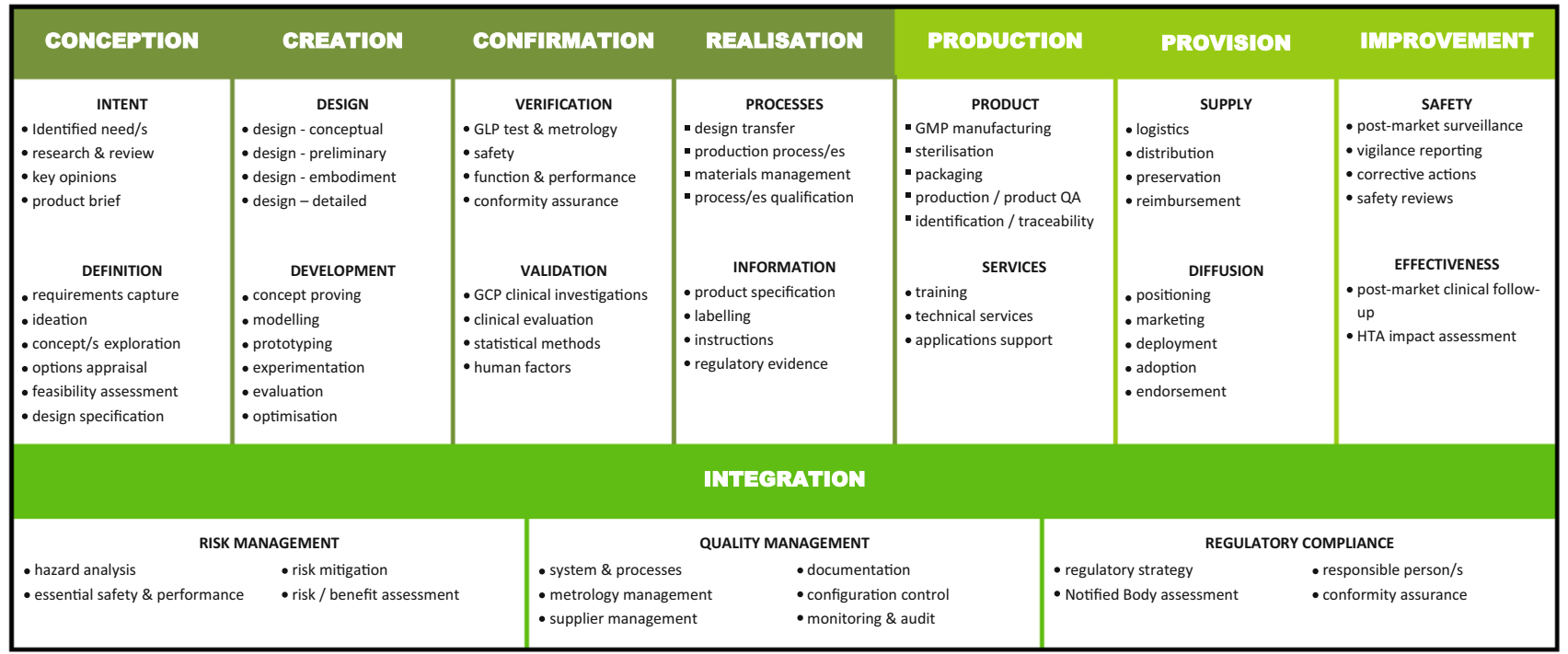

Fig. 1 Medical Technology Innovation Pathway

confirm the prototype does what it set out to do. There will be restrictions on the designs, not just on what is technically possible but also what is acceptable within the highly regulated healthcare environment. It is important during these iterations to keep the Intent in mind; keep referring back to the original briefing to make sure that the designs are meeting the identified healthcare need; it is easy at this stage to allow the engineering design and development to drive the project, allow it to drift away from the original intention. Good engineering practice should ensure these design and development iterations are well managed and documented; key elements of which include a risk management plan, design file and regulatory compliance strategy. Working under an appropriate Quality Management System (ISO 13485 [7]) whilst always not essential, is nonetheless the best way to ensure success in this stage. A successful medical device will ultimately require the appropriate regulatory approval - for instance CE marking in Europe or 510(k) in the USA - for which appropriate technical documentation will be required [8]. Our experience tells us that it is never too soon to start collating this information. What can seem like a bureaucratic overhead in the beginning pays dividends in the long run as retrospectively collating evidence for a technical dossier is challenging at best and impossible at worst. We have seen examples of excellent innovative technology flounder at the regulatory compliance hurdle due to poor or non-existent design and technical files.

At some point a final prototype will be produced which has been designed, developed and tested and can demonstrate, in the laboratory, that it meets the design brief. This then needs to be validated through appropriate clinical studies in the healthcare setting. This validation stage can be difficult and daunting for non-healthcare professionals. Indeed, even people working in the healthcare environment can find it challenging if unaccustomed to navigating the research and ethic protocols. Although the process can seem intimidating, it is generally easy to follow once understood. The secret is to be prepared and adequately resourced: clinical studies require time and money; successful cheap shortcuts do not exist.

A robust study design is essential to ensure a successful outcome [9]. This will help ensure that all necessary practical requirements are identified early so that adequate funds are requested. A well-documented study plan will help identify funding requirements as well as facilitate ethics committee and local research approvals, healthcare provider permissions, and any necessary regulatory approvals. Successful clinical studies often share similar characteristics: they are simple and tailored to a patient group; designed to address clear questions of clinical relevance; have the most appropriate choice of 


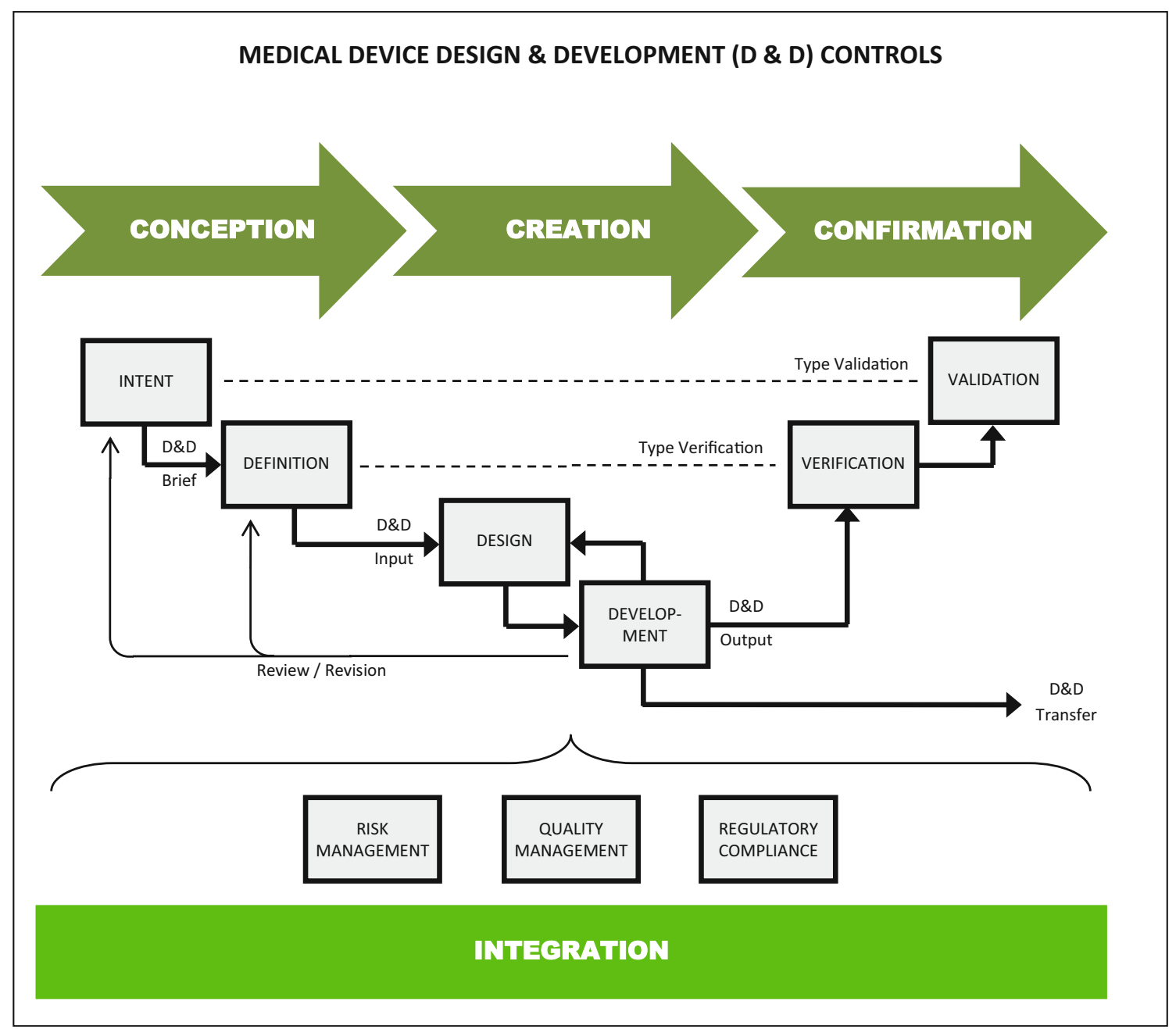

Fig. 2 Medical Technology Design \& Development Controls

control arm (where required) and have robust blinding of intervention or appropriately blinded outcome assessments (as necessary). Blinding in medical device trials can be challenging or impossible so thought must be given to mitigate this.

There is no substitute for experience in this area so it is necessary to partner with a clinical trials manager or healthcare statistician when: considering your trial design; choosing an appropriate outcome; providing justification of the sample size; advising on appropriate randomisation methodology; drawing up a statistical analysis plan and handling and structuring collected data. Patient and public involvement (PPI) is also important to ensure that the question proposed is important and relevant to the people it directly affects and that the trial is practical and feasible. There is now a growing evidence base to support the positive impact that PPI can have on participation recruitment and retention in clinical studies. Many funders will require evidence of genuine PPI involvement as a condition of funding [9].

A Med Tech Company or University approaching a healthcare institution out of the blue with a medical devices research proposal is going to struggle. So here again is where the clinical engineers can support the process. While not expected to be a clinical trials manager or healthcare statistician, the local clinical engineer should establish good relationships with these professionals and support the external Med Tech developer engage effectively. A small spin out Med Tech company approached us recently looking to gather evidence to support their CE marking application. This was their first medical device and they needed support through the whole validation process. We were able to engage an experienced clinical trials manager and a medical statistician so that between us - company, clinical engineers, statistician and trials manager - we were able to design a study that answered the appropriate questions for the company's CE marking application, complied with local research and ethics requirements and made efficient use of hospital and company resources. This team-based approach worked well for all parties: the company got the required clinical evidence and the hospital got well managed, adequately funded, high quality research with good recruitment. 
The end of the clinical studies generally marks the completion of the Confirmation stage. There can be a tendency to allow this to become natural break in the pathway: the clinical and academic teams have completed their elements, often papers have been published, technical files completed, proof of concept confirmed, and prototypes validated in the healthcare setting. Early investment - usually through publicly funded research grants or charities - is coming to an end and the route to market - through scale up, manufacturing, marketing, sales, distribution and delivery - is often viewed as a separate process; as someone else's responsibility with funding primarily through commercial backers (venture capitalists, business angels, company reserves or commercial loans). In our experience this is one of the biggest, and most common, mistakes in the healthcare technology innovation pathway. For one thing it is generally naive to believe that a manufacturer who has not been fully engaged in the development stages can be handed a prototype and be expected to scale up to a production model, manufacturer and distribute into a complex healthcare environment. Even with the best technical documentation in the world, it is a challenge for a manufacturer to pick up the baton at this stage, as it were, from a standing start. Always supposing, that is, that a suitable manufacturer can be identified who has the required capabilities and is prepared to take on what might well be viewed as a risky product.

\subsection{The so called 'Valley of Death'}

A further difficulty with this tendency to see the Invention Phase as separate from the Implementation Phase is that it has the effect of exacerbating the so called 'valley of death': that point in the development when product is too developed to continue to attract research funding but not yet mature enough to generate commercial funding. Much has been written about the challenge of technology businesses to bridge this gap $[10,11]$ but our experience tells us there are 5 key challenges for the healthcare innovative product traversing the gap.

\subsubsection{Healthcare environment}

A thorough understanding of the healthcare environment, the patient pathway, alternative treatments and diagnosis and the needs of the patient group are, of course, essential. The starting point to gaining this understanding is a health impact assessment: a relevant literature search and a review of current practice, including seeking the views of key opinion leaders. Always ask the patient; clinicians and developers might think they understand the patients' needs but there is no substitute for undertaking formal user needs elicitation utilising the Human Factors colleagues [6, 12]. It is surprising how often these exercises throw up important design considerations overlooked at the initial scoping stage. It is also important to make sure you take a wide view. A common story we see is where the product developer has a particular clinical or patient champion for their technology. The developers get carried away with the champion's enthusiasm and produce a fantastic device which meets their claimed need only to find at that point, that their champion's enthusiasm is not shared by the wider clinical or patient community.

Although most Med Tech developments start with the healthcare need in mind, this goal is sometimes lost or clouded before the final product is released. Several iterations of the design and development loop can see the product drift away from the original intent. It is therefore important to keep healthcare environment in mind through the process.

\subsubsection{Reimbursement}

Whatever the healthcare system - publically funded, insurance-based, or privately funded - somebody somewhere will need to pay for the medical device if it is to become a successfully adopted product. Understanding who that is and what motivates them to purchase the device is clearly important. We only have experience of reimbursement in the UK and mostly through the NHS and hesitate to proffer advice more widely beyond saying that this is a complex and usually poorly understood area. Therefore, local expertise will be required across the various healthcare systems.

\subsubsection{Regulations}

It is true that healthcare is a highly regulated industry and there are, therefore, significant considerations to be addressed before a product can be released onto the market and after. Regulations are often cited as a hurdle in the development and adoption of new medical device technology, but we encourage developers to view them more as safeguards ensuring the final products are safe and effective. Successful product development generally does not see the regulations as added element to be negotiated, but as an integral part of the initial design brief. Getting regulatory advice early and designing compliance from the outset is much easier than trying to retrospectively address regulatory issues with a product nearer the end of its development phase.

\subsubsection{Finance - health economics}

Generally, healthcare systems are finite: every pound/euro/ dollar spent on a new medical device is a pound/euro/dollar that cannot be spent on existing patient care. It is therefore important to be able to demonstrate that money spent on any new device will bring at least as much patient benefit as money spent elsewhere. In general terms the introduction of a new medical device into the healthcare system will deliver either improved, equivalent or reduced patient benefit when 
compared to current care and it will be either cheaper, about the same or more expensive. There are therefore potentially 9 states such a device can occupy as described in the Table 1 .

A device or intervention that delivers reduced patient benefit is unlikely to be adopted into the healthcare system even if it is cheaper than current care pathways. A device or intervention that brings equivalent patient benefit is only likely to be adopted into the healthcare system if it is cheaper than current care pathways. A device or intervention that delivers improved patient benefit is likely to be adopted into the NHS unless it is more expensive. Successful products therefore tend to demonstrate improved patient care at the same or equivalent costs or equivalent patient care at reduced costs and are identified in Table 1 with a ' $Y$ '. New devices or interventions identified in the central diagonal of Table 1 with a '?' might still be adopted but generally would need significant evidence and support of independent health bodies or royal colleges to influence buyers and commissioners.

\subsubsection{Partners}

The above discussions have illustrated the number of stakeholders required to navigate this far through the innovation pathway: clinicians, innovators, engineers, designers, regulatory experts, health statisticians, ethics experts, clinical trials managers, human factors experts, health economists, manufacturers and, of course, the patients and public. Bringing these people together and ensuring the appropriate level of engagement throughout the whole process is perhaps the biggest challenge facing the med tech developer. Access to specific experts at the right time is important but the 3 main stakeholders that need to be engaged throughout are: the clinical teams (including patients); the developers (usually academics) and industry. Our experience tells us that successful product development is most likely where this tri-partnership is established early and managed throughout.

Collectively, these elements might be defined as Product Realisation those steps necessary to take across the so called 'valley of death', though as we have seen this is not a discrete process that happens after the clinical studies and before the product manufacturer but a continuum of activity throughout the whole innovation pathway.

Table 1 The Matrix - A Simple Health

Economics Tool

\begin{tabular}{ccccc}
\hline & & \multicolumn{3}{l}{ Patient Benefit } \\
\cline { 3 - 5 } & & - & $=$ & + \\
\hline Cost & - & $?$ & $\mathrm{Y}$ & $\mathrm{Y}$ \\
& $=$ & $\mathrm{N}$ & $?$ & $\mathrm{Y}$ \\
& + & $\mathrm{N}$ & $\mathrm{N}$ & $?$ \\
\hline
\end{tabular}

\subsection{Implementation phase}

To this point in the linear model of the Innovation Pathway everything has been about the invention of the device. From here on, it is about getting that device manufactured, distributed and deployed to the people who need it; it is about implementation. See Fig. 3. The first two elements of this are Good Manufacturing Practice (GMP) and Good Distribution Practice (GDP) [13].

Good Manufacturing Practice (GMP) is the minimum standard that a medical device manufacturer must meet in their production processes. Products must: be of consistent high quality; be appropriate to their intended use; meet the requirements of the marketing authorisation (MA) or product specification. Good distribution practice (GDP) requires that devices are obtained from the approved supply chain and are consistently stored, transported and handled under suitable conditions, as required by the MA or product specification.

The Med Tech industry have excellent processes in place to deliver GMP and GDP and, provided they have been engaged early enough in the pathway and that the design and technical dossiers are good, these two elements are relatively straightforward.

The final stage of this linear model is post market surveillance to capture safety and effectiveness reviews which together allow for future product refinement and improvement. Rightly the primary purpose of post market stage is to maintain patient safety and ensure the benefits identified at the intent stage are achieved. However, a significant additional benefit from this work is identifying upgrade possibilities, or indeed complete redesigns, that would lead to better medical devices in the future. It is not uncommon, even with the most rigorously planned clinical studies, to produce unexpected findings once the device is released and used in the real world. Feedback from this 'real-world' testing can be invaluable. So, although the final stage of the linear model, this can also be considered the first stage of a cyclic model (see Fig. 4).

\section{The non-linear model}

So far we have described the innovation pathway as a number of discrete stages moving in one direction from initial conception through to final product release into the healthcare environment though we have been clear throughout of the limitations of viewing the innovation in this way. It is a convenient way to describe innovation development but in reality, it generally doesn't work like that. A UK government report [11] found that less than 1 in 5 successful technology innovations followed anything close to this route. The idea that publically funded research 'invents' and hands over to commercially funded industry to 'implement' is largely discredited. 


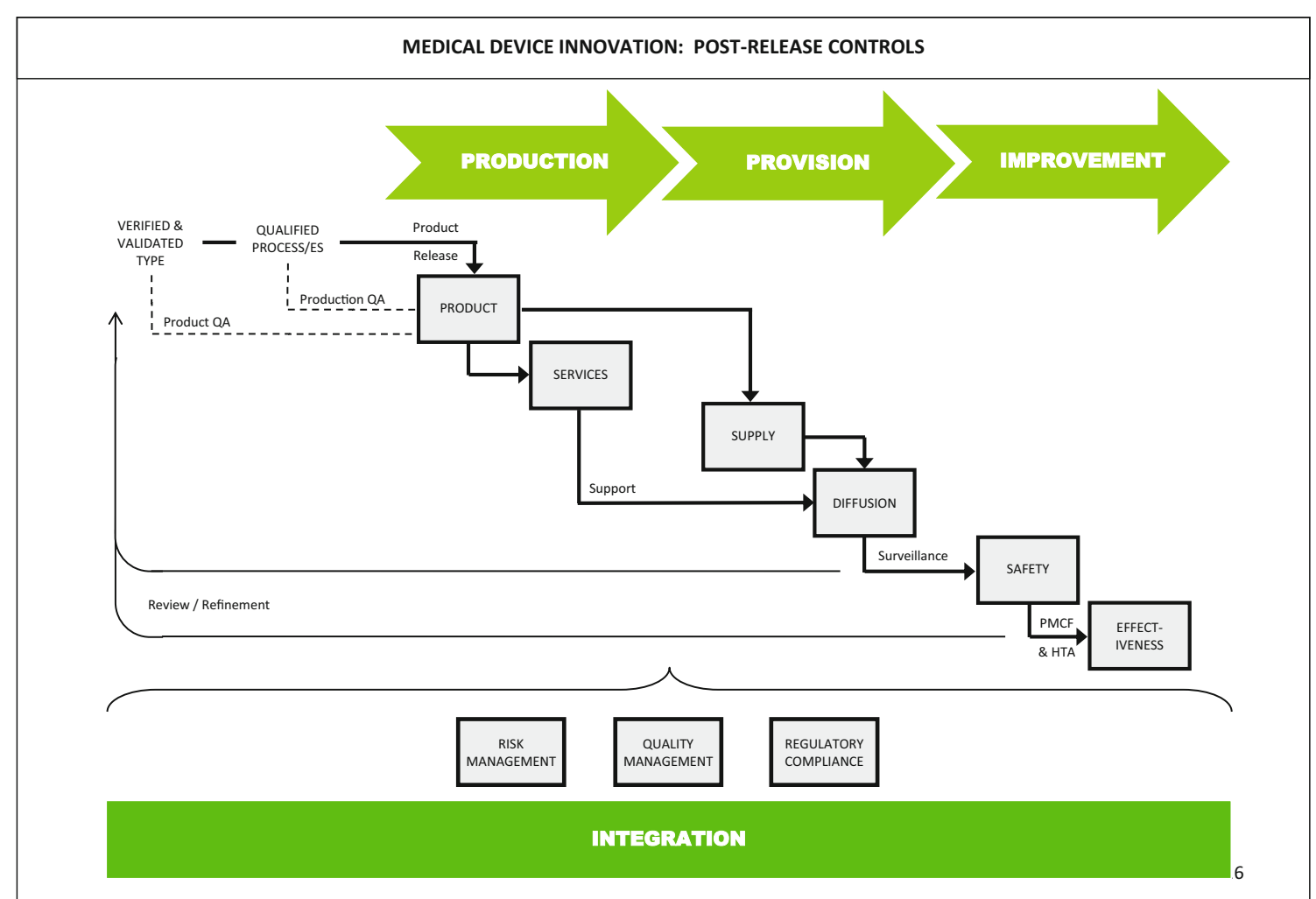

Fig. 3 Medical Technology Implementation Phase

There are a number of papers in the literature describing alternative models for technology innovation. For example, Carayannis and Campbell [14] describe the co-evolution and cross-integration of different innovation drivers (academia, industry, government and public) in the triple and quadruple helix models and Jucevoicius and Grumadaite [15] describe the innovation ecosystem using the approach of complex

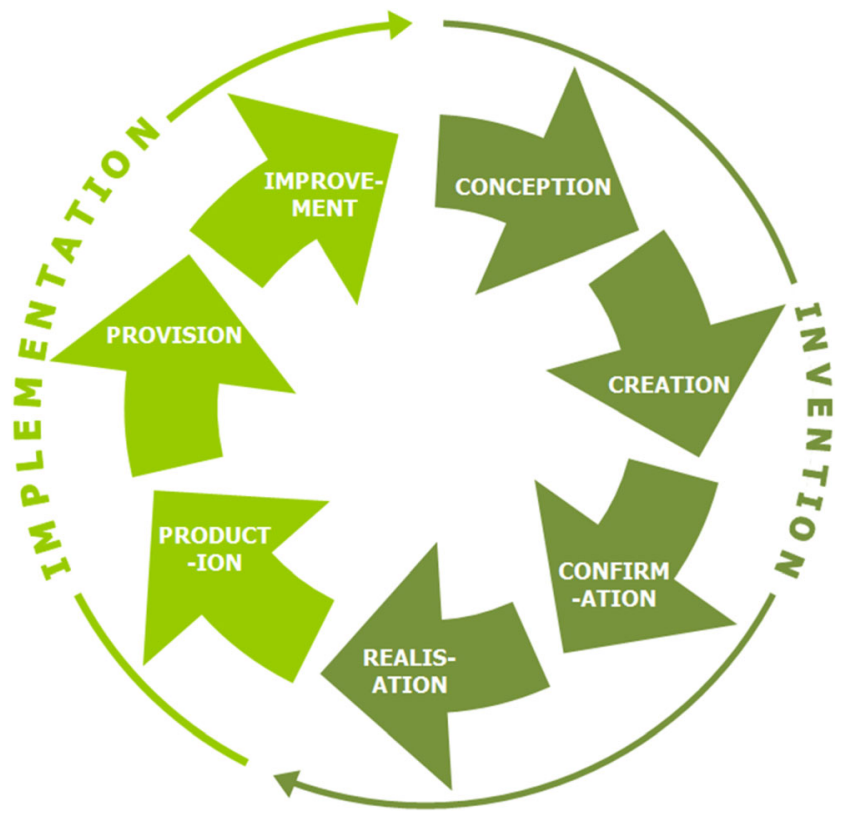

Fig. 4 Medical Technology Innovation Cycle theory. However, we prefer a simpler approach. We present a symbolic representation of this in Fig. 5, accepting it is figurative only. It is essentially the cyclic model but recognises that every stage around the cycle is influenced by, and influences, the other stages. Integration is at the 'hub' of this cycle. It holds the whole process together; facilitates the iterative feedback; controls risk management; manages relationships;

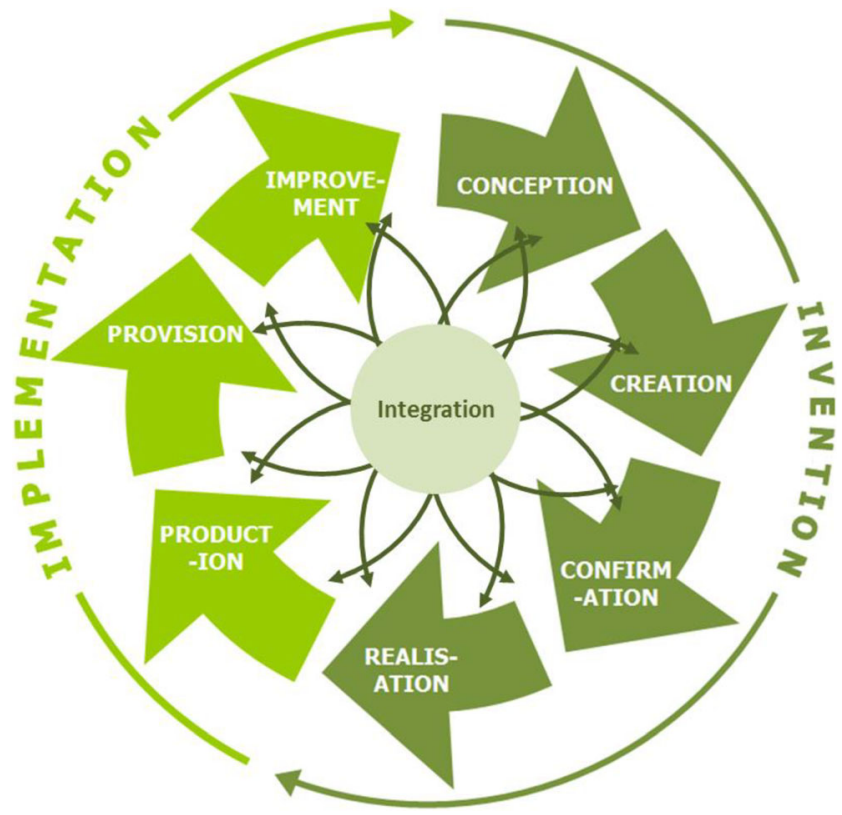

Fig. 5 Medical Technology Innovation Cycle - The Integration Hub 
provides Quality Management overview; ensures regulatory compliance and keeps the intent, the original vision, alive throughout the entire innovation path.

\section{The role of clinical engineers - the 'Integration Hub'}

Having been involved in many medical device product development projects over the years it became apparent that often no-one has the time, resources or capabilities to act as the 'hub'. Generally, the need for this function is overlooked and as a result neither research funding nor commercial funding is allocated, resulting in a series of predictable and avoidable problems occurring throughout the innovation pathway. Clinical Engineers might not be able to solve all these problems on their own but can, and we argue are best placed to, act as the integration hub for the innovation pathway. Embedded in the healthcare system, we have wide and diverse experience of the use of medical technology and established relationship with clinicians and patients. Moreover, with academic backgrounds and training we are natural bed-fellows of the university research teams so are ideally placed to facilitate those initial 'sparking' events. Our extensive clinical training and experience supports our intuitive understanding of the healthcare environment and our day jobs - of managing existing and introducing new technology in the clinical setting - enables us to establish good relationships with the Med Tech industry. We understand the regulatory framework; are experienced in project and risk management and often already work within Quality Management Systems. We might not be able to meet all the needs of the innovation pathway on our own - we are not health economists, human factors professionals, statisticians, ethics or clinical trials managers - but we are on the ground where these professionals work and can facilitate collaborative working with them all.

Recognising this missing 'Integration hub', and that clinical engineers are the professionals best equipped to create it, we established a group based within our Clinical Engineering team offering just this service. We call the group CHEATA (the Centre for Healthcare Equipment And Technology Adoption) and have been acting as the 'integration hub' for a number of healthcare technology innovation projects over the last 4 years; successfully supporting products over part or all of the innovation pathway [16].

\section{Key lessons}

After many years of supporting the adoption of healthcare technology including establishing a dedicated service (CHEATA) we have learnt a great deal about the innovation pathway, which we summarise here as 5 key lessons:

\subsection{Keep the patient in mind throughout}

We're in this industry to make a difference to patients. Work with patients and clinicians to establish the healthcare need early. Clearly define this and keep it central to the innovation. Don't allow engineering design, commercial interests, manufacturing limitations or anything else to obscure this vision.

\subsection{Partnerships}

Successful navigation of the innovation pathway for healthcare technology will require multi-stakeholder engagement. Recognise this and create the right partnerships between healthcare, academia and industry, as early as possible.

\subsection{It's never too early to utilise HTA}

Human factors, health impact assessments, health economics will all be vital to a successful product development. Don't leave these to the final stages but initiate them early as they will influence the final designs and ensure the best patient benefit and most economical product.

\subsection{Innovation is not linear}

It is convenient to talk about the stages of innovations as if it were a simple linear model. It isn't - it is a complex ecosystem which has many loops. Recognise this and create an 'integration hub' to manage the flow though the pathway.

\subsection{Clinical engineers should be at the heart of things}

We argue that Clinical Engineers are best placed to establish the 'integration hub'. Perhaps not traditionally core aspect of our roles we nonetheless need to develop our teams to support this function if innovative technology is to be successfully adopted into our healthcare systems.

\section{Conclusion}

Our experience over many years of supporting healthcare technology innovation, and specifically over the last 4 years through acting as the 'integration hub' for many projects, convinces us that Clinical Engineers can and should be centrally involved in this process. Not only are we best placed to deliver this function, we have the skills and experience to drive the innovation forward and the relationships necessary to deliver the key elements. It is good for us professionally, to extend our roles and raise our profiles in this way. It is good for the individual projects and innovations, as we can facilitate and support smoother and quicker adoptions. It will be 
essential for the future sustainable healthcare systems, as these new technologies will be vital if we are to meet the increasing demand for improvements in healthcare whilst at the same time delivering efficiencies so we can manage within our resources.

\section{Compliance with ethical standards}

Conflict of interest The authors declare no conflicts of interest.

Ethical approval This article does not contain any studies with human participants or animals performed by any of the authors.

Open Access This article is distributed under the terms of the Creative Commons Attribution 4.0 International License (http:// creativecommons.org/licenses/by/4.0/), which permits unrestricted use, distribution, and reproduction in any medium, provided you give appropriate credit to the original author(s) and the source, provide a link to the Creative Commons license, and indicate if changes were made.

\section{References}

1. The five year forward view, NHS England, October 2014, https:// www.england.nhs.uk/wp-content/uploads/2014/10/5yfv-web.pdf

2. Innovation Health and Wealth - Accelerating Adoption and Diffusion in the NHS, NHS England (2011).

3. Godin B. The Linear Model of Innovation, The Historical Construction of an Analytical Framework. Science, Technology \& Human Values, Vol 31, Issue 6 November 2006.

4. Smith PG, Reinertsen DG. Shortening the Product Development Cycle. Research-Technology Management Volume 35, 1992 Issue 3.

5. Grubb MR, Carpenter J, Crowe JA, Teoh J, Marlow N, Ward C, et al. Forehead reflectance photoplethysmography to monitor heart rate: preliminary results from neonatal patients. Physiol Meas. 2014 May;35(5):881-93.
6. Martin JL, Murphy E, Crowe JA, Norris BJ. Capturing user requirements in medical device development: the role of ergonomics. Physiol Meas. 2006;27:R49-62.

7. ISO 13485 , Medical devices - Quality management systems Requirements for regulatory purposes. March 2016.

8. Recommendation NB-MED/2.5.1/Rec5 Technical Documentation, Co-ordination of Notified Bodies Medical Devices (NB-MED) on Council Directives 90/385/EEC, 93/42/EEC and 98/79/EC (NB - at time of publication the EU Regulations have changed - new guidance anticipated).

9. NIHR Clinical Trials Toolkit, http://www.ct-toolkit.ac.uk/ routemap/trial-planning-and-design/ Accessed 2018.

10. Barr HS, Baker T, Markham KS, Kingon IA. Bridging the Valley of Death: Lessons Learned from 14 Years of Commercialization of Technology Education. Acad Manag Learn Educ. 2009;8(3):370 88.

11. Bridging the valley of death: improving the commercialisation of research. House of Commons Science and Technology Committee. 2014. Eighth Report of Session 2012-13.

12. Martin JL, Clark DJ, Morgan SP, Crowe JA, Murphy E. A usercentred approach to requirements elicitation in medical device development: A case study from an industry perspective. Appl Ergon. 2012;43(1):184-90.

13. Good manufacturing practice and good distribution practice, Medicines and Healthcare products Regulatory Agency, Dec 2014 (updated Oct 2017).

14. Carayannis E, Campbell D. 'Mode 3' and 'Quadruple Helix': Toward a 21 st century fractal innovation ecosystem. International Journal of Technology Management 46(3/4) . January 2009.

15. Jucevoicius G, Grumadaite K. Smart development of innovation ecosystem, 19th International Scientific Conference; Economics and Management 2014, ICEM 2014, 23-25.

16. CHEATA Case Studies. http://www.cheata.co.uk/case-studies Accessed 2018.

Publisher's note Springer Nature remains neutral with regard to jurisdictional claims in published maps and institutional affiliations. 